Научная статья

УДК 37.025.7

DOI https://doi.org/10.24866/VVSU/2073-3984/2021-3/217-228

В.С. Чернявская ${ }^{1}$

Т.А. Сидорова ${ }^{2}$

Владивостокский государственный университет экономики и сервиса

Владивосток. Россия

\title{
Психолого-педагогическая программа развития метакогнитивных способностей школьников
}

Обоснованы данные об актуальности метакогнитивных способностей школьников как основы результативности учения в русле отечественной педагогики, а также гуманистической педагогики и психологии, метакогнитивного подхода. Представлены данные педагогики и психологии о роли педагога в создании вариантов обучения - бессмысленного или осмысленного. Источником осмысленного становится, как минимум, предоставление ученику вариантов выбора, что делает его субъектом и предопределяет наличие осознанных результатов, а, следовательно, и метакогнитивных результатов. Рассмотрены подходы к развитию метакогнитивных способностей. Обоснована необходимость развития у школьников метакогнитивных способностей, выявлены низкие результаты диагностики (методика М. М. Кашапова). Дано описание части программы развития метакогнитивных способностей у школьников. Показана результативность программы: представлены статистические данные о росте метакогнитивных способностей, полученные с помощью углового преобразования Фишера. Разработанную программу можно использовать в других группах для повышения метакогнитивных способностей обучающихся.

Ключевые слова и словосочетания: студенты, образование, психолого-педагогическая программа, метакогнитивные способности.

\section{S. Chernyavskaya}

\section{T. A. Sidorova}

Vladivostok State University of Economics and Service

Vladivostok. Russia

1 Чернявская Валентина Станиславовна - д-р пед. наук, профессор, профессор кафедры философии и юридической психологии; e-mail: valstan13@mail.ru

${ }^{2}$ Сидорова Татьяна Анатольевна - ассистент кафедры философии и юридической психологии; e-mail: taniav96@mail.ru 


\section{Psychological and pedagogical program for the development of metacognitive abilities of schoolchildren}

\begin{abstract}
The data on the relevance of the metacognitive abilities of schoolchildren as the basis of the effectiveness of teaching in line with domestic pedagogy, as well as humanistic pedagogy and psychology, as well as the metacognitive approach are substantiated. The data of pedagogy and psychology on the role of a teacher in creating training options - meaningless or meaningful-are presented. The source of the meaningful becomes, at least, the provision of choice options to the student, which makes him a subject and determines the presence of conscious results, and, consequently, metacognitive results. The approaches to the development of metacognitive abilities by modern researchers are considered. The necessity of developing metacognitive abilities in schoolchildren is substantiated, low results of diagnostics of adolescent schoolchildren are shown, which are performed using the method of M. M. Kashapov. The description of the part of the program on the development of metacognitive abilities in schoolchildren is presented. The effectiveness of the program is shown. The statistical data on the effectiveness, which are performed using the angular Fisher transform, are shown. The text of the article allows you to use the developed program in other groups to improve the metacognitive abilities of students.
\end{abstract}

Keywords: image, students, education, psychological and pedagogical program, metacognitive abilities.

\section{Введение}

Современное образование переживает сложное время, которое отражает мировые процессы. Мир трансформируется, глобализируется, человек становится опасным для человека. Огромный интерес к гуманистическому подходу в образовании долгие годы сталкивается с препятствиями в администрировании образования, которое стало практически синонимом управления - манипуляции. Последние в большинстве случаев транслируются на коммуникацию в классе, аудитории. Адаптируясь к этой системе, молодой учитель, педагог, не имея собственного опыта образования гуманистического типа, полностью принимает эту стратегию и разворачивает для учеников обучение принудительного типа. Бессмысленность данного типа обучения для ученика резко снижает когнитивные результаты учения и провоцирует снижение мотивации. Собственная активность ученика в такой образовательной системе не оценивается и нивелируется.

По мнению В.А. Сухомлинского, школьника не стимулирует то, что «надо учиться», для него более важен путь учения и результаты, которые сам школьник может понять [8]. Наиболее важными результатами В. А. Сухомлинский считал научить школьника строить отношения с людьми, отношения в семье, понимать себя, свои интересы, развивать любознательность, самостоятельно выполнять задания [10]. Такие результаты образования, на наш взгляд, являются метакогнитивными.

Педагогика В.А. Сухомлинского, гуманизм К. Роджерса и его последователей, личностно-ориентированное обучение И.С. Якиманской, эффект «дидактической фасилитации» А.В. Карпова обосновывают предоставление ученику возможности выбора $[2 ; 8 ; 9 ; 10 ; 12]$. Делая собственный выбор, ученик становится субъектом учения и, соответственно, «получателем» учебного результата. При- 
чем этот результат может быть им осознан, то есть в определенной мере метакогнитивным результатом, поскольку он основан на рефлексии.

М.M. Кашапов рассматривает роль педагогических ресурсов в развитии метакогнитивных результатов ученика $[5 ; 6 ; 7]$. Ученый рассмотрел варианты ситуативного и надситуативного уровня мышления педагога. Надситуативный уровень мышления, в свою очередь, порождает возможность получения метапредметных результатов ученика, его метапредметных способностей.

В последние три десятилетия метакогнитивные способности превратились из в значительной степени забытой проблемы в одну из наиболее сложных областей теории и исследований в сфере педагогических наук [12-13]. Начиная с работы Дж. Флейвелла [15], который рассматривал метамышление как процесс регуляции мышления, концепция метапознания неразрывно связана с теориями обучения $[14 ; 15]$ и почти приравнивается к конструкции саморегулируемого обучения с точки зрения планирования, мониторинга и оценки обучения и решения проблем $[16 ; 17 ; 18]$. Этот рост интереса во многом определен формирующимся консенсусом среди учителей, педагогов, родителей и исследователей относительно важности способности учащихся самостоятельно управлять своими учебными процессами. В свете существующего в обществе акцента на обучение в течение всей жизни и экономического климата, требующего от людей быстрого приобретения новых навыков, этот рост теоретического и эмпирического интереса к метакогнитивным способностям людей самостоятельно и эффективно регулировать свое обучение, вероятно, продолжится.

В теории М. М. Кашапова метакогнитивные способности выражены термином «метапознание» и связаны, в первую очередь, с «надситуативностью»способностью субъекта увидеть ситуацию без привязки к внешним факторам, подняться «над ситуацией» и с помощью рефлексии собственной деятельности оценить её результативность, способствовать её совершенствованию в рамках поставленной задачи. Занятие такой позиции «над ситуацией» позволяет субъекту выполнять деятельность более успешно. В метапознании М. М. Кашапов выделяет метакогнитивную активность и метакогнитивные знания. Метакогнитивные знания - приобретенные знания о когнитивных процессах, позволяющие осуществлять контроль над познавательными процессами. Метакогнитивная активность включает в себя процессы приобретения информации (отслеживание и контроль), процессы трансформации, отбор, связь (соединение) и планирование. Метапознание позволяет субъекту более успешно осуществлять деятельность [1; $5 ; 6 ; 16 ; 17]$.

А.В. Карпов считает, что метакогнитивно одаренный субъект способен контролировать и регулировать свое поведение, подбирать метакогнитивные стратегии соответственно поставленным задачам, исследовать альтернативы решений, оценить уровень качества и эффективности решения задачи, а также определять жизненные задачи таким образом, чтобы последовательное их решение способствовало наилучшей адаптации [2].

Метакогнитивные способности школьника предопределяют способы самоорганизации, саморегуляции и качество учебного результата $[3 ; 5 ; 6]$. Школьник, 
обладая метакогнитивными способностями, может согласовывать внешние и внутренние условия осуществления деятельности, при этом учитывать возможности и ограничения по отношению к целям.

\section{Основная часть}

Чтобы проанализировать, на каком уровне находятся метакогнитивные способности школьников, авторы провели масштабное исследование: на выборке школьников подросткового возраста $(\mathrm{N}=56,28$ девочек, 28 мальчиков, 1214 лет) была проведена диагностика с помощью методики М. М. Кашапова [6, c. 365]. Результаты позволили заключить, что большинство испытуемых имеют низкий уровень метакогнитивных способностей $(0-10,35$ человек), 12 человек средние (10-15) и высокие 9 человек (15-22).

Эти данные свидетельствуют о низких метакогнитивных ресурсах подростков, что требовало изучения возможности развития и формирования метакогнитивных способностей у школьников.

Программа развития метакогнитивных способностей у школьников разрабатывалась и реализовывалась для семиклассников ( $\mathrm{N}=15$, из них 8 девочек, 7 - мальчиков, 13-14 лет) одной из школ г. Владивостока с согласия родителей во внеучебное время. Вел программу педагог-психолог школы. Общее количество времени 24 часа. Участие в программе - на добровольной основе. Программа состояла из следующих этапов: 1) введение; 2) актуализация, кульминация; 3) завершение.

Основными принципами реализации программы стала интеграция подходов экзистенциально-гуманистической педагогики и психологии. Использовались разные варианты предоставления школьникам выбора, возможности для отреагирования эмоциональных проблем и трудностей. Упражнения, вопросы и задания, включенные в программу, попадали в контекст метакогнитивной активности, компетенций и способностей, способности к осознанию приоритетов и стимулов развития, возможностей осознания и овладения метакогнитивными ресурсами самопознания, выработки внутренней позиции по отношению к фактам, снижению устремления удовлетворить чьи-то запросы, поиску возможности зависеть от себя, дистанцированию и способности находить удовольствие от учебного процесса независимо от оценок, что соответствует задачам программы.

Формат статьи не позволяет предоставить полное описание программы. Ниже представлена часть программы из 14 упражнений, которые могут быть распределены на несколько дней.

Предварительное собеседование с участниками группь (1 час)

Цель - исследование ожиданий, основ группового процесса; обсуждение ценностей и ограничений группы, информирование группы о том, как получить максимальную пользу, разъяснение необходимости соблюдения правил конфиденциальности; сообщение целей группы, информирование об использовании группового времени для исследования проблем, которые можно рассматривать в группе, принятие участниками решения о готовности участия в группе. 


\section{Занятие 1 (1 ч 35 мин)}

Целеполагание: способность справляться с трудностями.

Ход работы.

Приветствие (1 мин) (участники знакомы между собой и с ведущим, в силу чего этап знакомства исключен).

Упражнение 1. «Моё состояние» (10 мин)

Цель - разминка перед дальнейшей работой, раскрытие участников, сбор информации о готовности к дальнейшей работе.

Ход упражнения.

Ведущий просит участников выразить свое актуальное состояние в трёх категориях (я чувствую, я ощущаю, я думаю).

Упражнение 2. «Я есть» (15 мин)

Цель - актуализация чувства «Я есть в этом мире».

Ход упражнения.

Ведущий: «Мы вброшены в эту жизнь. Запрос от жизни: что ты будешь с этим делать? = твоя жизнь». Ведущий просит участников занять удобное положение, расслабиться, закрыть глаза, сказать про себя «я есть» и попытаться уловить возникающие ощущения (обратиться к собственным чувствам). Ведущий даёт необходимое количество времени на то, чтобы участники смогли уловить своё состояние, свои ощущения, чувства и эмоции. Далее участники высказываются о том, что они испытали. При необходимости ведущий просит отдельных участников задать себе вопрос: «Что не даёт мне тут быть?». Обсуждение.

Упражнение 3. «МОГУщество» (30 мин)

Цель - актуализация способностей; формирование чувства опоры.

Ход упражнения.

Ведущий просит участников ответить на вопросы: Что я хорошо умею? Какие у меня есть способности? Какие мои способности помогают мне быть в этом мире? Что я ощущаю, когда я что-то могу? Участники записывают ответ в блокнотах. Каждый участник по возможности высказывается. Обсуждение.

Ведущий: «Чем больше вы можете, тем прочнее ощущение вашего "мочь быть" = ОПОРА. Важно проживать своё "могу"» (уделять внимание тому, что я могу, что у меня получается). Осваивание новых видов деятельности даёт возможность переживать своё МОГУ.

Упражнение 4. «Мои силь»» (30 мин)

Цель - поиск возможных опор и сил.

Ход упражнения.

Ведущий просит участников задать себе вопрос и ответить на него: «Сколько видов сил у меня есть? Сколько я знаю? Какие? Насколько сильны во мне ощущения? Что меня держит? Что даёт мне веру в свою силу в первую очередь?». Участники записывают ответы в блокнот. Обсуждение.

Ведущий подводит участников к тому, чтобы видеть свою силу (тело, здоровье), предлагает поискать возможные силы и опоры. Обсуждение. 
Упражнение 5. Завериающее (20 мин)

Цель - подведение итога занятия; сбор обратной связи; удостоверение в оптимальном состоянии участников; выражение благодарности; рефлексия.

Ход упражнения.

Ведущий говорит об окончании занятия и просит участников поделиться своими впечатлениями о том, как они ощущали себя в ходе программы, что понравилось / не понравилось, что давалось легче / сложнее, с чем они уходят. Рефлексия.

\section{Занятие 2 (2 часа)}

Целеполагание - формирование способности справляться с трудностями.

Ход работы.

Приветствие.

Упражснение 1. «Моё состояние» (10 мин)

Цель - разминка перед дальнейшей работой, раскрытие участников, сбор информации о готовности к дальнейшей работе.

Ход упражнения.

Ведущий просит участников выразить свое состояние в трёх категориях (я чувствую, я ощущаю, я думаю), начиная с себя.

Упражнение 2. «Шаги преодоления неопределенности» (25 мин)

Цель - профилактика неопределенности, развитие навыков преодоления тревоги и неуверенности.

Ход упражнения.

Ведущий спрашивает о том, как действуют дети в ситуации неопределенности. Обсуждение.

Далее ведущий просит участников понять, что может им помочь справиться с неопределенной ситуацией (какая опора), что они могут сделать в данной ситуации. Обсуждение.

Ведущий отражает свой путь преодоления неопределенности и обобщает выводы. Акцентирует внимание на ценности, которая заключается в попытке.

Д/3: ведущий просит каждого из участников сделать то, что вызывает тревогу и неопределенные результаты.

Упражнение 3. «Место силь» (15-20 мин)

Цель - профилактика неуверенности.

Ход упражнения.

Ведущий предлагает учащимся удобно сесть, закрыть глаза и представить то место, где они могут быть, где спокойно, защищённо, расслабленно. «Куда я побегу в ситуации беды?» Участники по желанию рассказывают о своих местах.

Ведущий: «Это чувство следует возобновлять, наполняться от него. Бывать чаще в этих местах или хотя бы вспоминать».

Упражнение 4. «Дьхание» (10 мин)

Цель - телесная релаксация; ощущение телесного пространства. 


\section{Ход упражнения.}

Ведущий просит участников расслабиться и сделать несколько глубоких вдохов-выдохов. После участники делятся своими ощущениями.

Ведущий: минимальное пространство, доступное нам - мочь дышать.

Дыхание - критерий «мочь быть». Насколько вы занимаете это пространство? Каково ваше дыхание?

Упражнение 5. «Доверяю. Принимаю» (20-25 мин)

Цель - актуализация роли доверия.

Ход упражнения.

Ведущий просит участников подумать над следующими вопросами: Сколько принятости другими я получал в детстве? Кто эти люди? Могу ли я их вспомнить? Сколько принятости я в себе несу? При необходимости участники фиксируют ответы в блокнотах. Обсуждение.

Ведущий вновь просит участников подумать над следующими вопросами: Где мы встречаем доверие? Где доверяю я? Где доверяют мне? Какую роль доверие играет в моей жизни? При необходимости участники фиксируют ответы в блокнотах. Далее обсуждение.

Ведущий: «Доверие - составляющая повседневной жизни. Возможность бытия в этом мире. Доверия много. Чаще всего оно неосознанно. «До веры»- всегда есть риск. Не факт, что ничего не случится» (приводит примеры).

Упражнение 6. Завершающее (20 мин)

Цель - подведение итога занятия; сбор обратной связи; удостоверение в оптимальном состоянии участников; выражение благодарности; рефлексия.

Ход упражнения.

Ведущий говорит об окончании занятия и просит участников поделиться своими впечатлениями о том, как они ощущали себя в ходе консультативного процесса, что понравилось/не понравилось, что давалось легче/сложнее, с чем они уходят. Рефлексия.

Упражнение 7. «Нравится»

Цель - актуализация ценностных оснований жизни.

Ход работы.

Ведущий просит участников вспомнить свой обычный день с момента пробуждения и записать в блокноты то, что им нравится (например, чашка кофе с утра и т.д.). Участники отвечают на вопросы, делятся своим опытом.

Ведущий: «Важно в повседневной жизни отмечать даже те моменты, которые кажутся совсем мелкими. Переживание чувства «нравится» позволяет формировать чувство ценности жизни, ценности момента».

Упражснение 8. «Свобода и ответственность»

Цель - самодистанцирование по отношению к «нравится».

Ход упражнения.

Ведущий: «Желание определяет нашу «зливость». Но человек не обязан идти за каждым своим «хочу». Нет свободы без ответственности. Важно впустить «нравится» в свою жизнь, но мочь от него отделиться, чтобы мочь его проживать». Ведущий просит участников привести примеры из своей жизни, когда они 
отказываются от того, что им нравится (например, пост, отказ, аскетизм). Участники высказываются в порядке возникновения мыслей.

Упражнение 9. «Нравится и надо»

Цель - разграничение понятий ценность и «нравится».

Ход упражнения.

Ведущий: «Иногда «нравится» может перейти в систему «надо» (обязанности). В такие моменты важно прислушиваться к себе, понять, хочу или не хочу делать что-то именно сегодня, то ли это время, те ли у меня силы, хочу ли я прожить это «нравится» здесь и сейчас. Есть «ценность», а есть «нравится», и ценность не всегда может нравится». Участники приводят примеры из своей жизни.

Упражнение 10. «Биография "нравится"»

Цель - актуализация ценности моментов жизни.

Ход упражнения.

Ведущий просит участников вспомнить свою жизнь начиная с детства до нынешнего момента и отследить изменения их «нравится». «Как это было?» Участники погружаются в воспоминания, при необходимости фиксируют информацию в блокнотах. Обсуждение.

Упражнение 11. «Мои отночения»

Цель - актуализация способности вступать в отношения.

Ход упражнения.

Ведущий: «Подумайте о том, какие у вас есть отношения. Проживаете ли вы отношения с близкими людьми, с самим собой?». Участники обдумывают предложенные вопросы. Далее ведущий просит участников изобразить в своих блокнотах круг их отношений. Участники фиксируют изображение в блокнотах. Обсуждение.

Упражснение 12. «Время»

Цель - кристаллизация ценности через время.

Ход упражнения.

Ведущий задаёт участникам вопрос: «Что такое время?». Обсуждение.

Ведущий: «Время - единица измерения жизни». Ведущий просит участников подумать о том, как они распоряжаются своим временем, как они его тратят. Обсуждение.

Ведущий: «То, во что мы вкладываем время, ценно для нас. То, на что мы тратим время, - это то, ради чего мы живем». Ведущий просит участников подумать, чему они уделяют больше времени, для каких людей всегда есть время, у кого есть время для них самих. Участники при необходимости фиксируют ответы в блокнот. Ведущий: «Как то, на что вы тратите время, соотносится с тем, что ценно для вас?». Обсуждение.

Ведущий: «Чтобы ценность оставалась ценностью, ей необходимо уделять время. Если такого желания не возникает, пересмотрите свою систему ценностей подобно книжному шкафу, расставьте всё на полочки». 
Упражнение 13. «Близость»

Цель - формирование способности устанавливать близкие отношения.

Ход упражнения.

Ведущий: «Все мы обречены на отношения, они могут быть близкими и не очень». Ведущий просит участников подумать над следующими вопросами: Насколько я могу устанавливать близость? Где я чувствую себя по-настоящему живым? Чем меня пугает близость? Обсуждение. Ведущий: «Можете ли вы быть близкими с собой? Что этому мешает?».

Упражнение 14. "Внутреннее "Да"»

Цель - формирование способности выстраивания личных границ.

Ход упражнения.

Ведущий: «Постоянно находясь в отношениях, бывает трудно отделить «своё» от «чужого». Насколько хорошо вы умеете проводить границы между собой и другим человеком? Умеете ли вы это делать? Делаете?». Участники обдумывают ответы. Обсуждение.

Ведущий: «В ситуациях, когда мы затрудняемся провести собственные границы, поможет внутреннее «да». Необходимо обратиться к себе с вопросом: «Какой ответ вызывает у меня эта ситуация?». Важно стремиться проводить границы, иначе мы говорим «нет» своей ценности». Обсуждение.

Участникам программы была предложена анкета обратной связи. Анализ полученных результатов показал позитивный отклик участников, где все пятнадцать респондентов оценили актуальность своего участия в программе и расценили его как полезный для них опыт.

Итоговая диагностика развития метакогнитивных способностей показала, что все 15 семиклассников показали более высокие способности к метакогнитивным результатам. Из них 6 человек продемонстрировали высокий уровень метакогнитивных способностей, 4 - средний уровень и 5 низкий. Для анализа результативности реализации программы для группы из 15 школьников их показатели метакогнитивных способностей сравнивались до участия в экспериментальной программе и после нее. С этой целью использовался критерий углового преобразования Фишера. Гипотеза Н0 состоит в предположении, что различия до и после участия в программе достоверно не различаются. Н1 состоит в предположении о том, что различия в результатах являются достоверными. Категория «есть эффект» показывала число школьников с высоким и средним уровнем метакогнитивных способностей, категория «нет эффекта» подразумевала низкий уровень метакогнитивных способностей. Показатели развития метакогнитивных способностей рассматривались в соответствии с нормами М.М. Кашапова [6, с. 365]. 
Статистические данные результативности программы. Четырехпольная таблица с данными углового преобразования Фишера

\begin{tabular}{|l|c|c|c|}
\hline Группа («до», «после») & $\begin{array}{c}\text { «Есть эффект»: задача } \\
\text { решена }\end{array}$ & $\begin{array}{c}\text { «Нет эффекта», задача } \\
\text { не решена }\end{array}$ & \multirow{2}{*}{ Суммы } \\
\cline { 1 - 3 } & Количество учеников & Количество учеников & \\
\hline Группа «до» & $4(26,7 \%)$ & $11(73,3 \%)$ & $15(100 \%)$ \\
\hline Группа «после» & $10(66,7 \%)$ & $5(33,3 \%)$ & $15(100 \%)$ \\
\hline
\end{tabular}

Коэффициент Фишера $\varphi^{*} э м п ~=2.259$. Полученное эмпирическое значение $\varphi^{*}$ находится в зоне неопределенности. Н0 отвергается, что говорит о достоверности различий между показателями развития метакогнитивных способностей у школьников до участия в программе и после нее.

Результативность программы свидетельствует о том, что метакогнитивные способности и активность школьников увеличились. Они научились концентрации умению управлять своим вниманием, фокусироваться на задании, приобретать информацию, выбирать главные идеи для последующего освоения, изучения, способны отделять важное от второстепенного, организовывать свое время.

\section{Выводы}

Развитие метакогнитивных способностей школьников позволяет им овладеть собственными ресурсами: понимать себя, развивать рефлексию, ставить цели, структурировать время, действовать в ситуации неопределенности, овладевать эмоциональными возможностями, а также многими конкретными, прикладными видами умений и навыков, которые позволяют лучше учиться и выстраивать отношения с собой и другими людьми. Разработка и реализация программы, которая показала свою результативность, позволяет педагогам и психологам воспроизвести ее для групп других школьников, что может дать положительные результаты в росте личностной зрелости и способности решать учебные и жизненные задачи.

1. Кашапов С. М. Акмеологические и психологические механизмы творческого мышления профессионала в контексте метакогнитивного подхода // Вестник Тверского государственного университета. Серия: Педагогика и психология. - 2009. - № 1. C. 4-12.

2. Карпов А.В. Когнитивные и мотивационные детерминанты эффекта дидактической фасилитации // Актуальные проблемы совершенствования высшего образования: тезисы докладов XIV всероссийской научно-методической конференции, Ярославль, 31 марта 2020 года. - Ярославль: Филигрань, 2020. - С. 124-126.

3. Карпов А. В. Метакогнитивные способности в структуре личности // Методология современной психологии, Ярославль, 15-17 мая 2016 года. - Ярославль: Ярославский государственный университет им. П.Г. Демидова, 2015. - С. 53-63. 
4. Карпов А. В., Скитяева И. М. Психология рефлексии. - Москва: ИП РАН, 2002. $284 \mathrm{c}$.

5. Кашапов М.M. Когнитивное и метакогнитивное понимание структурнодинамических характеристик профессионального мышления // Творческая деятельность профессионала в контексте когнитивного и метакогнитивного подходов / под ред. М.М. Кашапова, Ю.В. Пошехоновой. - Ярославль: ЯрГУ, 2012. - С. 35-121.

6. Кашапов М.М. Творческая деятельность профессионала в контексте когнитивного и метакогнитивного подходов. - Ярославль: ЯрГУ, 2012. - 384 с.

7. Метакогнитивные основы конфликтной компетентности / под науч. ред. проф. М.М. Кашапова. - Ярославль: ЯрГУ, 2012. - 428 с.

8. Роджерс К., Фрейберг Д. Свобода учиться. - Москва: Смысл, 2002. - 527 с.

9. Сухомлинский В.А. Потребности человека в человеке. - 2-е изд. - Москва: Сов. Россия, 1981. - 96 с. (Человек среди людей).

10. Якиманская И. С. Личностно-ориентированное обучение в современной школе. Москва, 2004. - 224 с.

11. New developments in the field of self-regulated learning / B. Schmitz, M. Schmidt, M. Landmann, C. Spiel // Journal of Psychology. - 2007 - Vol. 215, Is. 3. - P. 153-156.

12. Winne P. H. A perspective on state-of-the-art research on self-regulated learning / P. H. Winne // Instructional Science. - 2005. - Vol. 33, Is. 5-6. - P. 559-565.

13. Flavell J. H. Metacognition and cognitive monitoring: A new area of cognitivedevelopmental inquiry // American Psychologist. - 1979. - Vol. 34, Is. 10. - P. 906-911.

14. Metacognition and learning: conceptual and methodological considerations / M. V. J. Veenman, B. H. Van, A. M. Hout-Wolters, P. Afflerbach // Metacognition and Learning. - 2006. - Vol. 1. - P. 3-14.

15. Boekaerts M. Self-regulated learning: where we are today International Journal of Educational Research // International Journal of Educational Research. - 1999. - Vol. 31, Is. 6. P. 445-457.

16. Paris S. G., Paris A. H. Classroom applications of research on self-regulated learning // Educational Psychologist. - 2001. - Vol. 36, Is. 2. - P. 89-101.

\section{References}

1. Kashapov S.M. Akmeologicheskie i psihologicheskie mekhanizmy tvorcheskogo myshleniya professionala $\mathrm{v}$ kontekste metakognitivnogo podhoda // Vestnik Tverskogo gosudarstvennogo universiteta. Seriya: Pedagogika i psihologiya. - 2009. - № 1. - S. 4-12.

2. Karpov A. V. Kognitivnye i motivacionnye determinanty effekta didakticheskoj fasilitacii // Aktual'nye problemy sovershenstvovaniya vysshego obrazovaniya: tezisy dokladov XIV vserossijskoj nauchno-metodicheskoj konferencii, YAroslavl', 31 marta 2020 goda. Yaroslavl': Filigran', 2020. - S. 124-126.

3. Karpov A. V. Metakognitivnye sposobnosti v strukture lichnosti // Metodologiya sovremennoj psihologii, Yaroslavl', 15-17 maya 2016 goda. - Yaroslavl': Yaroslavskij gosudarstvennyj universitet im. P.G. Demidova, 2015. - S. 53-63.

4. Karpov A.V., Skityaeva I.M. Psihologiya refleksii. - Moskva: IP RAN, 2002. - 284 s.

5. Kashapov M. M. Kognitivnoe i metakognitivnoe ponimanie strukturno-dinamicheskih harakteristik professional'nogo myshleniya // Tvorcheskaya deyatel'-nost' professionala $\mathrm{v}$ kontekste kognitivnogo i metakognitivnogo podhodov / pod red. M. M. Kashapova, Yu. V. Poshekhonovoj. - Yaroslavl': YArGU, 2012. - S. 35-121.

6. Kashapov M. M. Tvorcheskaya deyatel'nost' professionala $\mathrm{v}$ kontekste kognitivnogo i metakognitivnogo podhodov. - Yaroslavl': YArGU, 2012. - $384 \mathrm{~s}$. 
7. Metakognitivnye osnovy konfliktnoj kompetentnosti / pod nauch. red. prof. M. M. Kashapova. - Yaroslavl': YArGU, 2012. - 428 s.

8. Rodzhers K., Frejberg D. Svoboda uchit'sya. - Moskva: Smysl, 2002. - 527 s.

9. Suhomlinskij V.A. Potrebnosti cheloveka v cheloveke. - 2-e izd. - Moskva: Sov. Rossiya, 1981. - 96 s. (Chelovek sredi lyudej).

10. Yakimanskaya I.S. Lichnostno-orientirovannoe obuchenie v sovremennoj shkole. Moskva, 2004. - 224 s.

(C) В.С. Чернявская, 2021

(C) Т.А. Сидорова, 2021

Для цитирования: Чернявская В. С., Сидорова Т. А. Психолого-педагогическая программа развития метакогнитивных способностей школьников // Территория новых возможностей. Вестник Владивостокского государственного университета экономики и сервиса. - 2021. - Т. 13, № 3. - С. 217-228.

For citation: Chernyavskaya V.S., Sidorova T.A. Psychological and pedagogical program for the development of metacognitive abilities of schoolchildren, The Territory of New Opportunities. The Herald of Vladivostok State University of Economics and Service, 2021, Vol. 13, № 3, pp. 217-228.

DOI https://doi.org/10.24866/VVSU/2073-3984/2021-3/217-228

Дата поступления: 10.09.2021. 